Check for updates

Cite this: RSC Adv., 2017, 7, 33627

\title{
Kinetics and mechanistic investigation into the degradation of naproxen by a UV/chlorine process $\uparrow$
}

Received 23rd April 2017

Accepted 28th June 2017

DOI: $10.1039 / \mathrm{c} 7 \mathrm{ra04540a}$

rsc.li/rsc-advances

\author{
Yu-qiong Gao, DD *a Nai-yun Gao, ${ }^{\mathrm{b}}$ Wen-hai Chu, ${ }^{\mathrm{b}}$ Qin-lin Yang ${ }^{\mathrm{a}}$ and Da-qiang Yin ${ }^{\mathrm{b}}$
}

In this study, UV irradiation combined with chlorine (UV/chlorine) was used to degrade naproxen (NPX), a typical non-steroidal anti-inflammatory drug (NSAID) widely used for the treatment of symptoms associated with inflammation, in water. Compared with UV irradiation alone and direct chlorination, the UV/chlorine process shows a synergistic effect on NPX degradation. The effects of different factors, including the chlorine dose, solution $\mathrm{pH}$, and the presence of $\mathrm{Cl}^{-}, \mathrm{HCO}_{3}{ }^{-}$or humic acid (HA), on NPX degradation in the UV/chlorine process were investigated. The results indicated that the degradation of NPX followed pseudo-first-order kinetics in all cases, and the rate constant increased as the chlorine dose increased and decreased as the $\mathrm{pH}$ increased. The effects of the water matrix on UV/chlorine treatment were species-dependent. The NPX degradation rate was inhibited by the presence of $\mathrm{HCO}_{3}{ }^{-}$ and $\mathrm{HA}$ but significantly improved by $\mathrm{Cl}^{-}$. LC/MS/MS analysis indicated that NPX decomposition in the UV/chlorine process was associated with decarboxylation, demethylation and hydroxylation. These results indicate that the UV/chlorine process is a promising technology for the treatment of water polluted by emerging contaminants, such as NPX. However, UV/chlorine can notably enhance the formation of disinfection by-products compared to direct chlorination, which should be carefully considered when integrating this process into drinking water treatment schemes.

\section{Introduction}

In recent years, pharmaceutical and personal care products (PPCPs) have been the subject of increasing concern around the world as emerging contaminants. PPCPs are widely used as veterinary therapeutic drugs to prevent and treat human and animal diseases and improve the quality of life of humans. ${ }^{1}$ Many PPCPs can be easily transported and distributed in water bodies due to their high polarity and low volatility. ${ }^{2}$ Because of their extensive applications and poor removal in conventional wastewater treatment plants, PPCPs are ubiquitous in aquatic environments. ${ }^{3}$ PPCPs are commonly detected in waters at concentrations ranging from $n g \mathrm{~L}^{-1}$ to low $\mu \mathrm{g} \mathrm{L}^{-1}$. Even these trace levels are enough to cause hazardous effects on human health and ecosystems. ${ }^{\mathbf{4} 5}$ As a typical PPCP, naproxen belongs to the class of non-steroidal anti-inflammatory drugs (NSAIDs) and is widely used in the treatment of arthritis, ankylosing spondylitis, acute muscle pain, and other symptoms associated with inflammation. Most of these drugs are usually partly

${ }^{a}$ School of Environment and Architecture, University of Shanghai for Science and Technology, Shanghai 200093, China. E-mail: gaoyq@usst.edu.cn; Tel: +86 21 55275979

${ }^{b}$ State Key Laboratory of Pollution Control and Resource Reuse, Key Laboratory of Yangtze River Water Environment, Ministry of Education, College of Environmental Science and Engineering, Tongji University, Shanghai 200092, China

$\dagger$ Electronic supplementary information (ESI) available. See DOI: 10.1039/c7ra04540a metabolized or simply pass through human body. NPX is frequently detected in WWTFs, surface water, or even groundwater. ${ }^{6-8}$ It has been reported that naproxen can impair the lipid peroxidation system of bivalves and change microbial community structures to yield antibiotic resistance. ${ }^{9}$ Like most other PPCPs, naproxen seems to be resistant to conventional wastewater treatment. According to Carballa et al., the overall removal efficiency of NPX in a sewage treatment plant was approximately $40-55 \%{ }^{10}$ Therefore, it is important to make use of technologies that focus on removing such drugs from points of discharge.

Advanced oxidation processes (AOPs) have often gained recognition as a promising approach towards removing recalcitrant organic pollutants in water. The hydroxyl radicals $\left({ }^{\circ} \mathrm{OH}\right)$ formed during AOPs, with a high reduction potential of $2.9 \mathrm{~V}$ in AOPs, are capable of destroying or mineralizing most organic compounds with high reaction rate constants. ${ }^{\mathbf{1 1}}$ The combination of UV irradiation and chlorine (UV/chlorine) has recently been examined as an effective AOP for PPCPs removal from water. ${ }^{12}$ Several reactive species, including ${ }^{\circ} \mathrm{OH}$ and reactive chlorine species (RSC) such as ${ }^{\circ} \mathrm{Cl}$ and $\mathrm{Cl}_{2}{ }^{--}$, can be formed through reactions occurring in the UV/chlorine system (eqn (1)(5)). ${ }^{13}{ }^{\circ} \mathrm{Cl}$ and $\mathrm{Cl}_{2}{ }^{-}$have reduction potentials of $2.4 \mathrm{~V}$ and $2.0 \mathrm{~V}$, respectively, which are comparable to that of ${ }^{\circ} \mathrm{OH}$, and can degrade the target contaminants. ${ }^{12}$

$$
\mathrm{HOCl} \leftrightarrow \mathrm{H}^{+}+\mathrm{OCl}^{-}
$$




$$
\begin{gathered}
\mathrm{HOCl}+h v \rightarrow \cdot \mathrm{OH}+{ }^{\cdot} \mathrm{Cl} \\
\mathrm{OCl}^{-}+h v \rightarrow \cdot \mathrm{Cl}+\cdot \mathrm{O}^{-} \\
\cdot \mathrm{O}^{-}+\mathrm{H}_{2} \mathrm{O} \leftrightarrow \cdot \mathrm{OH}+\mathrm{OH}^{-} \\
\cdot \mathrm{Cl}+\mathrm{Cl}^{-} \leftrightarrow \mathrm{Cl}_{2}^{\cdot-}
\end{gathered}
$$

In general, the UV/chlorine process combines the advantages of $\mathrm{UV} / \mathrm{H}_{2} \mathrm{O}_{2}$ and chlorination processes, which is an economical, efficient, and easy to operate AOP. The UV/ chlorine process is more efficient than UV photolysis or chlorination in the degradation of atrazine (ATZ), and the degradation efficiency of ATZ is sensitive to the solution $\mathrm{pH}$, as well as common anions in real waters. ${ }^{\mathbf{1 4}}$ There is a clear synergistic effect between UV and chlorine on the degradation of carbamazepine during the UV/chlorine process, and the initial oxidation products of CBZ resulted from hydroxylation, carboxylation and hydrogen atom abstraction by ${ }^{\circ} \mathrm{OH}$ and ${ }^{\circ} \mathrm{Cl}^{15} \mathrm{Wu}$ et al. compared the change in the acute toxicity of a trimethoprim solution at different reaction times in the chlorination and UV/chlorine processes, and found that the acute toxicity resulting from UV/chlorine was lower than that from direct chlorination, with the same removal rate of trimethoprim. ${ }^{16}$ Additionally, UV irradiation can effectively inactive chlorine-tolerant pathogenic microorganisms (e.g., Cryptosporidium parvum and Giardia lamblia) and is often used in conjunction with chlorine in a complementary manner. ${ }^{17}$ However, as a chlorine-derivate treatment, this process runs the risk of forming chlorinated products during degradation. It has been reported that more disinfection byproducts (DBPs) precursors were formed during the UV/ chlorine process than during UV irradiation or direct chlorination, which is of concern in water treatment processes. ${ }^{18}$

Therefore, the aim of this study is to evaluate the removal efficiency of NPX by the UV/chlorine process, along with the influence of factors such as chlorine doses, solution $\mathrm{pH}, \mathrm{Cl}^{-}$, $\mathrm{HCO}_{3}{ }^{-}$and humic acid (HA) on NPX removal in water. Moreover, the degradation pathways of NPX during UV/chlorine were proposed according to LC/MS/MS analysis. Finally, we compare the disinfection by-products (DBPs) formation during the treatment of NPX by direct chlorination and UV/chlorine processes.

\section{Materials and methods}

\subsection{Materials and reagents}

Naproxen was purchased from Sigma-Aldrich (USA). Sodium hypochlorite $(\mathrm{NaOCl})$ containing $5 \%$ free chlorine was obtained from Sinopharm Chemical Reagent Co., Ltd. (Shanghai, China). HPLC-grade acetonitrile used as the mobile phase was obtained from J. T. Baker (USA). DBPs standard solutions were also purchased from Sigma-Aldrich. All other chemicals were at least of analytical grade and were used without further purification. All solutions were prepared with ultrapure water produced from a Milli-Q water purification system (Millipore, USA).

\subsection{Experimental procedures}

All experiments were conducted in a collimated beam apparatus (Fig. $\mathrm{S} 1 \dagger){ }^{19}$ The equipment consists of a low-pressure UV $\mathrm{Hg}$ lamp (UV-C, $75 \mathrm{~W}$, Philips, Netherlands), a lampshade used to parallel the light, two reaction dishes, two magnetic stirrers, and two rest pier. The average irradiation strength on the solution was calculated to be approximately $261 \mu \mathrm{W} \mathrm{cm} \mathrm{cm}^{-2}$, using atrazine chemical actinometry. ${ }^{20}$ Before each experiment, the lamp was turned on for at least $30 \mathrm{~min}$ to stabilize the lamp output. The degradation of NPX by UV/chlorine process was conducted by spiking specific amounts of chlorine into a 100 mL testing solution containing $25 \mu \mathrm{M}$ NPX and $10 \mathrm{mM}$ phosphate buffer to give an initial chlorine dosage of 125-375 $\mu \mathrm{M}$ and $\mathrm{pH}$ of 5-9, and oxidation was initiated once the Petri dishes were moved under the collimated beam apparatus. UV photolysis alone and direct chlorination of NPX were conducted without spiking with chlorine solution and UV irradiation, respectively. At each determined time, $0.8 \mathrm{~mL}$ of sample was collected into an HPLC vial containing excess $\mathrm{Na}_{2} \mathrm{~S}_{2} \mathrm{O}_{3}$ to quench the residual chlorine. And the samples were immediately analyzed by HPLC for NPX concentration and LC/MS/MS for degradation products. In addition, $10 \mathrm{~mL}$ or $40 \mathrm{~mL}$ of reaction solution was transferred into a glass volumetric bottle for TOC or DBPs analysis, respectively.

\subsection{Analytical methods}

The concentration of NPX was measured by using a high performance liquid chromatography (HPLC) (Waters e2695, USA) equipped with a symmetry C18 column $(4.6 \mathrm{~mm} \times 250$ $\mathrm{mm}, 5 \mu \mathrm{m}$, Waters, USA) by an UV detector wavelength of $230 \mathrm{~nm}$. The mobile phase for naproxen consisted of 70\%/30\% (v/v) acetonitrile and $0.1 \%$ formic acid in Milli-Q water at a flow rate of $0.8 \mathrm{~mL} \mathrm{~min}{ }^{-1}$. The sample injection volume was $10 \mu \mathrm{L}$. The evolution of the reaction mixtures was also monitored using a TU-19 UV-vis spectrophotometer (Puxi, Beijing, China).

A stock solution of free chlorine was prepared from $5 \%$ liquid sodium hypochlorite and standardized by the DPD $(N, N$ diethyl-p-phenylenediamine, Sigma, >99\%) colorimetric method.

The intermediate products of NPX formed during UV/ chlorine process were analyzed by LC/MS/MS, which consisted of an HPLC system (Waters 2010, USA) and a TSQ Quantum mass spectrometer (ESI source, Thermo Scientific Inc., USA) with a Hypersil Gold C18 column $(2.1 \times 150 \mathrm{~mm}, 5 \mu \mathrm{m})$. The sample injection volume was $10 \mu \mathrm{L}$. The A and B mobile phases were $0.1 \%$ formic acid in Milli-Q water and acetonitrile, respectively, at a flow rate of $0.25 \mathrm{~mL} \mathrm{~min}^{-1}$. The elution started at $5 \% \mathrm{~B}$, then linearly increased to $95 \% \mathrm{~B}$ over $15 \mathrm{~min}$ and was kept at $95 \%$ B for $5 \mathrm{~min}$. After that, the elution was decreased to 95\% B in the following $1 \mathrm{~min}$ and kept at 95\% B for $4 \mathrm{~min}$. The ESI conditions were as follows: spray voltage $=4500 \mathrm{~V}$, sheath gas pressure $=20 \mathrm{au}$, aux gas pressure $=5 \mathrm{au}$, capillary temperature $=320{ }^{\circ} \mathrm{C}$. MS chromatograms were obtained in both total ion current (TIC) mode, using full scans $(\mathrm{m} / \mathrm{z} 50-400)$ for mass spectra acquisition, and selected ion monitoring (SIM) mode. 
The degree of NPX mineralization was quantified by measurement of the reduction in the total organic carbon (TOC) in water. TOC analysis was measured using a TOC analyzer (Shimadzu TOC 5050A) equipped with an ASI5000 autosampler.

DBPs were quantified using a purge and trap sample concentrator (Eclipse 4660, OI, USA) and gas chromatography/ mass spectrometry (GC/MS) (QP2010, Shimadzu, Japan). Details on the analysis of DBPs are available elsewhere. ${ }^{21}$

\section{Results and discussion}

\subsection{Preliminary studies}

The results of NPX degradation by UV alone, direct chlorination and the UV/chlorine process are shown in Fig. 1.

Generally, the degradation of NPX by UV irradiation alone was negligible, resulting in the removal of $6.5 \%$ in $30 \mathrm{~min}$. The corresponding pseudo-first-order rate constant was 0.00223 $\min ^{-1}$. In contrast, it seems that NPX is vulnerable to both chlorination and the UV/chlorine processes, as $77.8 \%$ and $98.5 \%$ of NPX was removed after 30 min by direct chlorination and UV/chlorine, respectively. The degradation of NPX by direct chlorination and UV/chlorine also followed pseudo-first-order kinetics, and the corresponding rate constants were 0.053 $\mathrm{min}^{-1}$ and $0.135 \mathrm{~min}^{-1}$, respectively.

Although the molar absorptivity of NPX at $254 \mathrm{~nm}$ can reach $4900 \mathrm{M}^{-1} \mathrm{~cm}^{-1}$, the low efficiency photolysis of NPX attributes to its low quantum yield of $0.0093 \mathrm{~mol}$ per einstein. ${ }^{22}$ It has been demonstrated that chlorine oxidation can readily transform NPX into intermediates. ${ }^{23}$ In addition, the synergistic effect was clear in the UV/chlorine process, as the degradation rate of NPX increased by 1.54 times in the UV/chlorine process, compared to that in direct chlorination. The combination of UV and chlorine results in a stronger oxidation than direct chlorination due to the formation of highly reactive radical species, such as hydroxyl radicals $\left({ }^{\circ} \mathrm{OH}\right)$ and chlorine atoms $\left({ }^{\circ} \mathrm{Cl}\right)$, which have

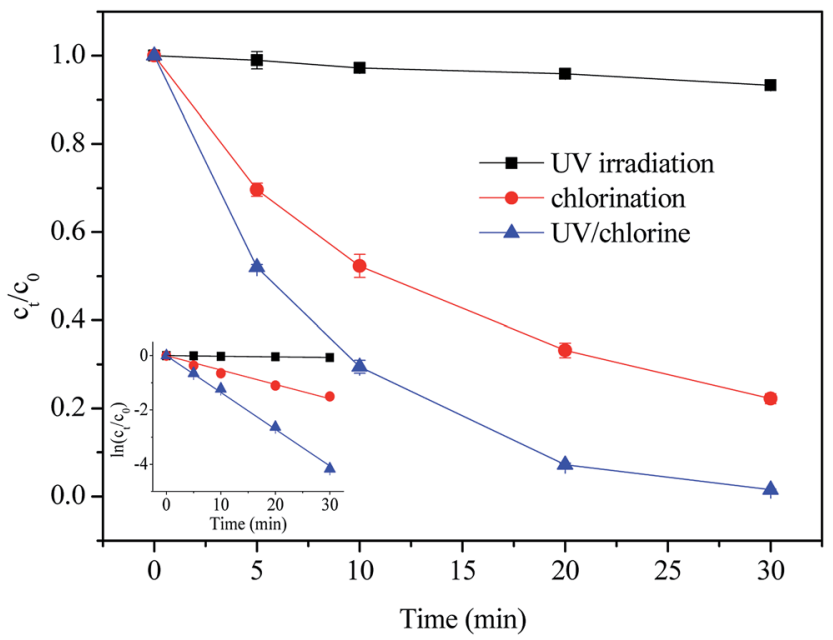

Fig. 1 Degradation of NPX by UV irradiation alone, direct chlorination and UV/chlorine process. Conditions: $[\mathrm{NPX}]_{0}=25 \mu \mathrm{M}$, $[\text { chlorine }]_{0}=$ $250 \mu \mathrm{M}, \mathrm{pH}=7$. a stronger oxidation ability than free chlorine. ${ }^{12}$ An additional experiment was conducted to confirm the role of radicals in NPX degradation. As shown in Fig. S2, $\uparrow$ various concentrations of tert-butanol (TBA) inhibited NPX degradation to different extent during the UV/chlorine process. As seen, the rate constant decreased from $0.135 \mathrm{~min}^{-1}$ to $0.058 \mathrm{~min}^{-1}$, respectively, with the addition of TBA increased from $0 \mathrm{mM}$ to $25 \mathrm{mM}$ $\left([\mathrm{TBA}]_{0} /[\text { chlorine }]_{0}=0-100\right)$. And the rate constant almost kept constant with further increased in TBA concentration. The reported reaction rate constants for TBA with ${ }^{\circ} \mathrm{OH}$ and ${ }^{\circ} \mathrm{Cl}$ are $6 \times$ $10^{8} \mathrm{M}^{-1} \mathrm{~s}^{-1}$ and $3 \times 10^{8} \mathrm{M}^{-1} \mathrm{~s}^{-1}$, respectively, and thus, TBA may compete for ${ }^{\circ} \mathrm{OH}$ and ${ }^{\circ} \mathrm{Cl}$, resulting in a decrease in the NPX degradation rate. ${ }^{24,25}$ Moreover, it seems that the addition of $25 \mathrm{mM}$ TBA $\left([\mathrm{TBA}]_{\mathrm{o}} /[\text { chlorine }]_{0}=100\right)$ can enough inhibited the NPX degradation by ${ }^{\circ} \mathrm{OH}$ and ${ }^{\circ} \mathrm{Cl}$. The above results indicated that both direct chlorination and radical oxidation contributed to the degradation of NPX by UV/chlorine oxidation.

\subsection{Effect of chlorine dose}

Semi-logarithmic graphs of $[\mathrm{NPX}]_{t} /[\mathrm{NPX}]_{0}$ with different chlorine doses as a function of time are shown in Fig. 2.

NPX degradation by both direct chlorination and UV/ chlorine under different doses of chlorine is well fit by pseudo-first-order kinetics. With chlorine only, the degradation rate of NPX increased from 0.020 to $0.104 \mathrm{~min}^{-1}$ as the ratio of $[\text { chlorine }]_{0} /[\mathrm{NPX}]_{0}$ increased from 5 to 15 . Since direct chlorination plays an important role in the degradation of NPX, an increased concentration of chlorine will accelerate NPX degradation. In addition, the degradation rate of NPX by UV/chlorine also increased from 0.057 to $0.215 \mathrm{~min}^{-1}$ upon increasing the ratio of [chlorine $]_{0} /[\mathrm{NPX}]_{0}$ from 5 to 15 . The reactive radicals, including ${ }^{\circ} \mathrm{OH}$ and ${ }^{\circ} \mathrm{Cl}$, increased as the free chlorine increased, which strengthened the oxidation in the UV/chlorine process. Moreover, the degradation rate constant of NPX in the UV/ chlorine process exhibited a linear tread as a function of

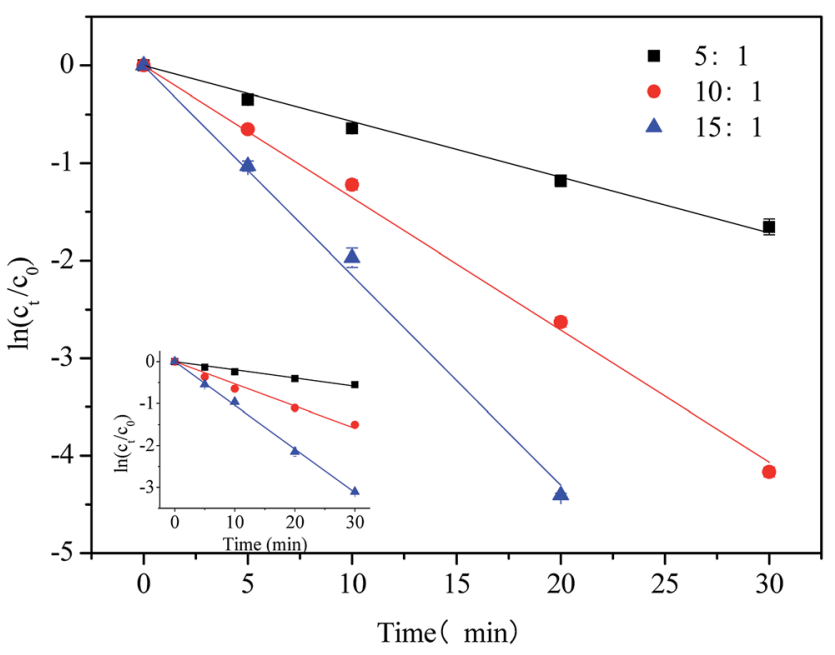

Fig. 2 Effect of [chlorine $]_{0} /[\mathrm{NPX}]_{0}$ on the degradation of NPX by direct chlorination and UV/chlorine process. Conditions: $[\mathrm{NPX}]_{0}=25 \mu \mathrm{M}$, $[\text { chlorine }]_{0} /[\mathrm{NPX}]_{0}=5: 1,10: 1$, and $15: 1, \mathrm{pH}=7$. 
chlorine dose $\left(k=0.631[\text { chlorine }]_{0}-0.0221, R^{2}=0.99\right)$. Previous studies reported that an increase in the initial chlorine dose did not continuously ensure an increase in the degradation rate of NPX due to the scavenging of the reactive species by excess free chlorine. ${ }^{12,14}$ However, the inhibitory effect of excess chlorine was not observed, probably because the chlorine dose did not reach the critical level at which NPX degradation begins to slow. Considering that the effect of chlorine dose on the UV photolysis of NPX can be neglected, we determined that the contribution of the radical oxidation pathway slightly decreased from $61 \%$ to $50 \%$ as the ratio of $[\text { chlorine }]_{0} /[\mathrm{NPX}]_{0}$ increased from 5 to 15 .

\section{3. $\quad$ Effect of $\mathbf{p H}$}

Semi-logarithmic graphs of $[\mathrm{NPX}]_{t} /[\mathrm{NPX}]_{0}$ at varies solution $\mathrm{pH}$ as a function of time are shown in Fig. 3.

As seen, the degradation rate of NPX in both direct chlorination and the UV/chlorine process is highly $\mathrm{pH}$-dependent. As the solution $\mathrm{pH}$ increased from 5 to 9 , the pseudo-first-order rate constant of direct chlorination decreased from 0.392 to $0.003 \mathrm{~min}^{-1}$, while that of the UV/chlorine process decreased from 0.475 to $0.028 \mathrm{~min}^{-1}$, respectively.

Because the ratio of chlorine dissociation products $(\mathrm{HOCl}$ and $\left.\mathrm{OCl}^{-}\right)$is susceptible to the solution $\mathrm{pH}\left(\mathrm{p} K_{\mathrm{a}, \mathrm{HOCl}}=7.5\right)$, chlorine exists mainly as $\mathrm{HOCl}$ at lower $\mathrm{pH}$, and $\mathrm{HOCl}$ gradually transformed into $\mathrm{OCl}^{-}$as the solution $\mathrm{pH}$ increased; therefore, less $\mathrm{HOCl}$ is available for NPX oxidation. ${ }^{26}$ It has been reported that the oxidation capacity of $\mathrm{OCl}^{-}$towards drugs is weak compared with that of $\mathrm{HOCl}^{27}$ Moreover, naproxen is a weak acid with a $K_{\mathrm{a}}$ of 4.15 , and thus, the deprotonation of NPX increased as the $\mathrm{pH}$ increased. ${ }^{28}$ Therefore, the reaction between the two anionic forms at higher $\mathrm{pH}$ is less efficient than that at lower $\mathrm{pH}$. During the UV/chlorine process, despite the fact that both $\mathrm{HOCl}$ and $\mathrm{OCl}^{-}$photolysis can produce ${ }^{\circ} \mathrm{OH}$ radicals, showing quantum yields at $254 \mathrm{~nm}$ of 1.4 and 0.97 ,

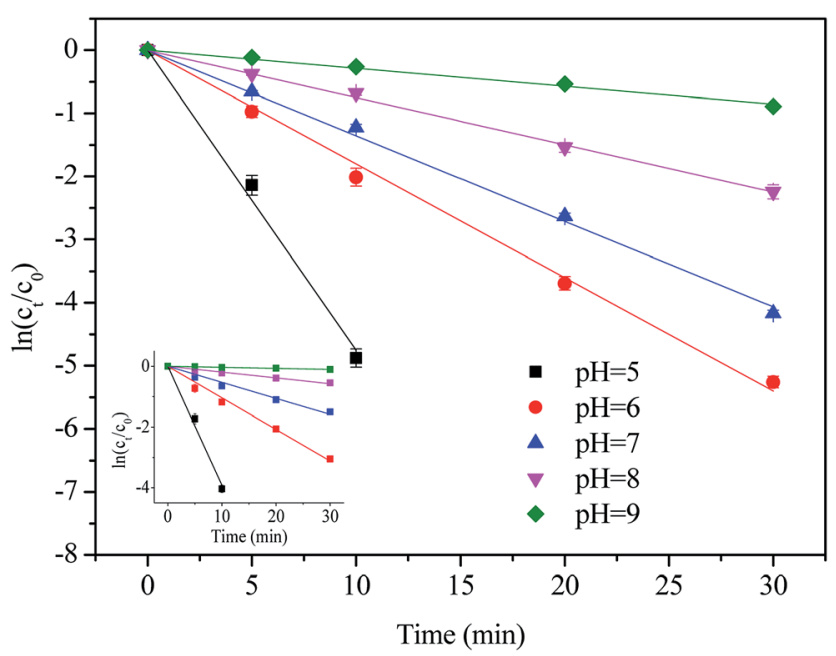

Fig. 3 Effect of solution $\mathrm{pH}$ on the degradation of NPX by direct chlorination and UV/chlorine process. Conditions: $[N P X]_{0}=25 \mu \mathrm{M}$, [chlorine] $_{0}=250 \mu \mathrm{M}, \mathrm{pH}=5,6,7,8$ and 9 . respectively, the formation of ${ }^{\circ} \mathrm{OH}$ and ${ }^{\circ} \mathrm{Cl}$ was reduced at higher $\mathrm{pH}$ as determined by the decreased quantum yield. ${ }^{12}$ Of note, both $\mathrm{HOCl}$ and $\mathrm{OCl}^{-}$are also ${ }^{\circ} \mathrm{OH}$ and ${ }^{\circ} \mathrm{Cl}$ scavengers, and the rate constants of $\mathrm{HOCl}$ with ${ }^{\circ} \mathrm{OH}$ and ${ }^{\circ} \mathrm{Cl}$ are lower than that of $\mathrm{OCl}^{-}$(eqn (6)-(9))..$^{12,29}$

$$
\begin{gathered}
\cdot \mathrm{OH}+\mathrm{HOCl} \rightarrow \mathrm{H}_{2} \mathrm{O}+{ }^{\cdot} \mathrm{ClO}, k=8.46 \times 10^{4} \mathrm{M}^{-1} \mathrm{~s}^{-1} \\
\cdot \mathrm{OH}+\mathrm{OCl}^{-} \rightarrow \mathrm{OH}+\cdot \mathrm{ClO}, k=9.0 \times 10^{9} \mathrm{M}^{-1} \mathrm{~s}^{-1} \\
\cdot \mathrm{Cl}+\mathrm{HOCl} \rightarrow \mathrm{H}^{+}+\mathrm{Cl}^{-}+{ }^{\cdot} \mathrm{ClO}, k=3.0 \times 10^{9} \mathrm{M}^{-1} \mathrm{~s}^{-1} \\
\cdot \mathrm{Cl}+\mathrm{OCl}^{-} \rightarrow \mathrm{Cl}^{-}+{ }^{\cdot} \mathrm{ClO}, k=8.2 \times 10^{9} \mathrm{M}^{-1} \mathrm{~s}^{-1}
\end{gathered}
$$

As a result, UV/chlorine achieves a higher removal efficiency at lower $\mathrm{pH}$. In addition, the contribution of the radical oxidation pathway increased from $17.0 \%$ to $81.3 \%$ as the solution $\mathrm{pH}$ increased from 5 to 9 .

\subsection{Effect of aqueous matrix species}

The $\mathrm{Cl}^{-}$anions, inorganic carbon $\left(\mathrm{HCO}_{3}{ }^{-} / \mathrm{CO}_{3}{ }^{2-}\right)$ and humic acid (HA) are common constituents in natural water, which have been demonstrated to have different impacts on the degradation of targeted pollutants by radical-based AOPs, it is necessary to evaluate the effect of these constituents. ${ }^{15}$ Semilogarithmic graphs of $[\mathrm{NPX}]_{t} /[\mathrm{NPX}]_{0}$ under different matrix species $\left(\mathrm{Cl}^{-}, \mathrm{HCO}_{3}{ }^{-}\right.$and $\left.\mathrm{HA}\right)$ as a function of time are shown in Fig. 4. As seen, their effects on NPX decomposition were different. In the presence of $5 \mathrm{mM} \mathrm{Cl}^{-}$, the NPX degradation rate increased by $169.8 \%$ and $49.6 \%$ in the direct chlorination and UV/chlorine processes, respectively. The result is due to the fact that $\mathrm{Cl}_{2}$ can be formed from $\mathrm{HOCl}$ and $\mathrm{Cl}^{-}$, according to eqn (10), and the presence of $\mathrm{Cl}^{-}$shifts the reaction to the right. ${ }^{30}$ Since $\mathrm{Cl}_{2}$ is more electrophilic than $\mathrm{HOCl}$, its presence accelerates NPX degradation.

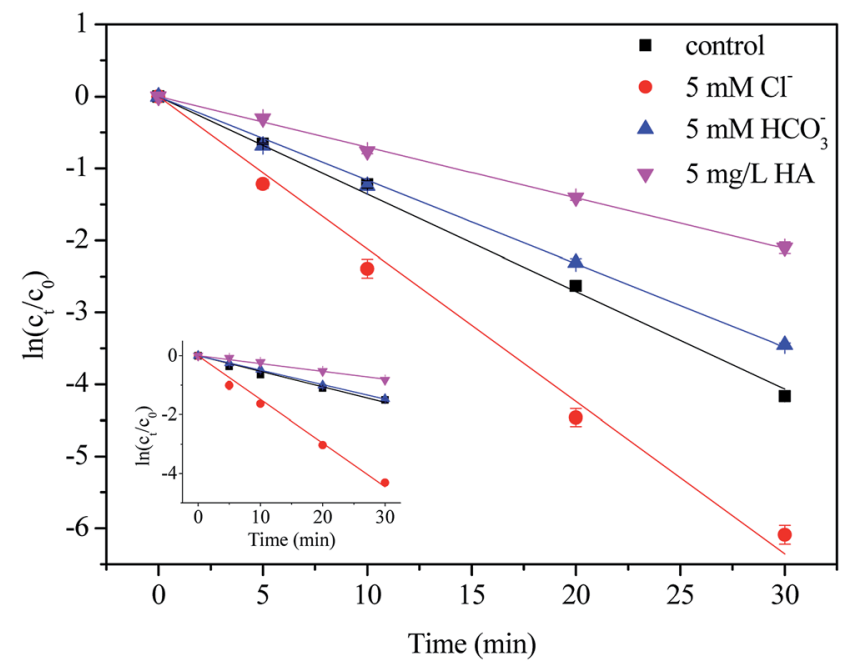

Fig. 4 Effect of matrix species on the degradation of NPX by direct chlorination and UV/chlorine process. Conditions: $[\mathrm{NPX}]_{0}=25 \mu \mathrm{M}$, [chlorine $]_{0}=250 \mu \mathrm{M}, \mathrm{pH}=7,\left[\mathrm{Cl}^{-}\right]=\left[\mathrm{HCO}_{3}{ }^{-}\right]=5 \mathrm{mM}, \mathrm{HA}=5 \mathrm{mg} \mathrm{L}^{-1}$. 


$$
\mathrm{HOCl}+\mathrm{H}^{+}+\mathrm{Cl}^{-} \leftrightarrow \mathrm{Cl}_{2}+\mathrm{H}_{2} \mathrm{O}
$$

On the other hand, ${ }^{\circ} \mathrm{Cl}$ and ${ }^{\circ} \mathrm{OH}$ produced during the UV/ chlorine process reacts rapidly with $\mathrm{Cl}^{-}$to form ${ }^{\circ} \mathrm{Cl}_{2}{ }^{-}$and $\mathrm{ClOH}^{--}$separately, which are more selective and may affect the degradation efficiency of NPX (eqn (11)-(15)). ${ }^{12}$ Altogether, $\mathrm{Cl}^{-}$ has a positive effect on NPX degradation in this study.

$$
\begin{gathered}
\mathrm{Cl}^{+\mathrm{Cl}^{-}} \rightarrow \mathrm{Cl}_{2}^{\cdot-}, k=6.5 \times 10^{9} \mathrm{M}^{-1} \mathrm{~s}^{-1} \\
\mathrm{Cl}_{2}^{\cdot-} \rightarrow \cdot \mathrm{Cl}+\mathrm{Cl}^{-}, k=1.1 \times 10^{5} \mathrm{~s}^{-1} \\
\mathrm{OH}^{-\mathrm{Cl}^{-}} \rightarrow \mathrm{ClOH}^{\cdot-}, k=4.3 \times 10^{9} \mathrm{M}^{-1} \mathrm{~s}^{-1} \\
\mathrm{ClOH}^{\cdot-} \rightarrow \cdot \mathrm{OH}+\mathrm{Cl}^{-}, k=6.1 \times 10^{9} \mathrm{~s}^{-1} \\
\mathrm{ClOH}^{\cdot-} \rightarrow \cdot \mathrm{Cl}+\mathrm{OH}^{-}, k=23 \mathrm{~s}^{-1}
\end{gathered}
$$

As for $\mathrm{HCO}_{3}{ }^{-}$, the degradation rate of NPX decreased by $29.6 \%$ during the UV/chlorine process and remained almost constant during direct chlorination. Once $\mathrm{HCO}_{3}{ }^{-}$was added to the solution, it would proceed to react, and the carbonate system would eventually reach equilibration. As the $\mathrm{p} K_{\mathrm{a}}$ values of $\mathrm{H}_{2} \mathrm{CO}_{3}$ are 6.35 and 10.33 , at neutral $\mathrm{pH}$, the primary compositions at equilibrium were $4.083 \mathrm{mM} \mathrm{HCO}_{3}{ }^{-} / 0.002 \mathrm{mM}$ $\mathrm{CO}_{3}{ }^{2-}$ with a $5 \mathrm{mM}$ initial concentration of $\mathrm{HCO}_{3}{ }^{-}$. Both $\mathrm{HCO}_{3}{ }^{-}$ and $\mathrm{CO}_{3}{ }^{2-}$ compete with NPX for ${ }^{\circ} \mathrm{OH}$ and ${ }^{\circ} \mathrm{Cl}$ due to their high rate constants with ${ }^{\circ} \mathrm{OH}$ and ${ }^{\circ} \mathrm{Cl}$, which reduces the degradation rate of NPX (eqn (16)-(18))..12,31

$$
\begin{aligned}
& \cdot \mathrm{OH}+\mathrm{HCO}_{3}^{-} \rightarrow \mathrm{H}_{2} \mathrm{O}+\mathrm{CO}_{3}{ }^{\cdot-}, k=8.5 \times 10^{6} \mathrm{M}^{-1} \mathrm{~s}^{-1} \\
& \cdot \mathrm{OH}+\mathrm{CO}_{3}{ }^{2-} \rightarrow \mathrm{CO}_{3}{ }^{--}+\mathrm{OH}^{-}, k=3.9 \times 10^{8} \mathrm{M}^{-1} \mathrm{~s}^{-1} \\
& { }^{\mathrm{Cl}}+\mathrm{HCO}_{3}{ }^{-} \rightarrow \mathrm{H}_{2} \mathrm{O}+\mathrm{CO}_{3}{ }^{--}, k=2.2 \times 10^{8} \mathrm{M}^{-1} \mathrm{~s}^{-1}
\end{aligned}
$$

In the presence of $5 \mathrm{mg} \mathrm{L}^{-1} \mathrm{HA}$, the degradation rate of NPX decreased by $50.9 \%$ and $61.5 \%$ in the direct chlorination and UV/chlorine processes, respectively. Initially, HA competes with NPX for oxidants and ${ }^{\circ} \mathrm{OH}$ and ${ }^{\circ} \mathrm{Cl}$. The reported rate constants between NOM and ${ }^{\circ} \mathrm{OH}$ and ${ }^{\circ} \mathrm{Cl}$ were $2.5 \times 10^{4}\left(\mathrm{mg} \mathrm{L}^{-1}\right) \mathrm{s}^{-1}$ and $1.3 \times 10^{4}\left(\mathrm{mg} \mathrm{L}^{-1}\right) \mathrm{s}^{-1}$, respectively. ${ }^{12,32}$ Furthermore, NOM can act as a UV inner filter, which reduces the rate at which chlorine photolysis produces ${ }^{\circ} \mathrm{OH}$ and ${ }^{\circ} \mathrm{Cl}^{12}$ Finally, $\mathrm{HA}$ can also consume chlorine directly.

\subsection{Degradation of NPX in natural water}

The potential of the UV/chlorine process and direct chlorination in removing NPX was examined using natural water samples. The samples were collected from one waterworks in Yixin City, Jiangsu Province. As shown in Table 1, the performance of NPX degradation by direct chlorination and the UV/chlorine process was significantly inhibited when using natural water due to the strong scavenging effects of anions and/or NOM, as discussed earlier. In addition, the UV/chlorine process seems to be more efficient and tolerant than direct chlorination for removing NPX from natural water. UV/chlorine was also more suitable for the removal of NPX in natural water. $E_{\mathrm{EO}}\left(\mathrm{kW} \mathrm{h} \mathrm{m}^{-3}\right.$ per order) was adopted to calculate the energy consumption by the UV/ chlorine process (eqn (19)). ${ }^{33}$

$$
E_{\mathrm{EO}}=\frac{P \times t \times 1000}{V \times 60 \times \log \left(c_{0} / c_{t}\right)}
$$

where $P$ is the total electrical power, $\mathrm{kW} ; t$ is the irradiation time, min; and $V$ is the volume of the treated solution, $\mathrm{L}$. The calculated $E_{\mathrm{EO}}$, which denotes the electricity cost, in ultrapure water, raw water and finished water was $213.20,1370.57$ and $654.14 \mathrm{~kW} \mathrm{~h} \mathrm{~m}^{-3}$, respectively.

\subsection{Intermediate product analysis and degradation pathway}

The UV-vis absorption spectra of the reaction mixtures as a function of time are shown in Fig. 5. NPX has a main absorption band centred at $230 \mathrm{~nm}$, a second band centred around $270 \mathrm{~nm}$, and a third band of lower intensity around $320 \mathrm{~nm}$. It is obviously that the main absorption band of NPX decreased in intensity as the reaction proceeds, indicating the NPX disappeared quickly during UV/chlorine process, and the change of the absorbance in the $230-270 \mathrm{~nm}$ region cannot be described with a simple exponential curve, suggesting the formation of the intermediates.

Besides NPX, eight intermediate products at detectable levels were identified by LC/MS/MS analysis. Their tentative structures, chromatograms and mass spectra are provided in Table S1, Fig. S3 and S4. $\dagger$ The intermediate products of NPX were denoted as P246, P186, P184, P200, P204, P264, P299 and P134.

P246 corresponds to the hydroxylated products of NPX, which was attributable to ${ }^{\circ} \mathrm{OH}$ attack. In addition, $\mathrm{P} 246$ has structural isomers with different retention times. However, the MS data information cannot distinguish the exact position of hydroxylation. According to Dulova et al., the methyl and

Table 1 The water quality parameters and degradation rate constants of different samples ${ }^{a, b}$

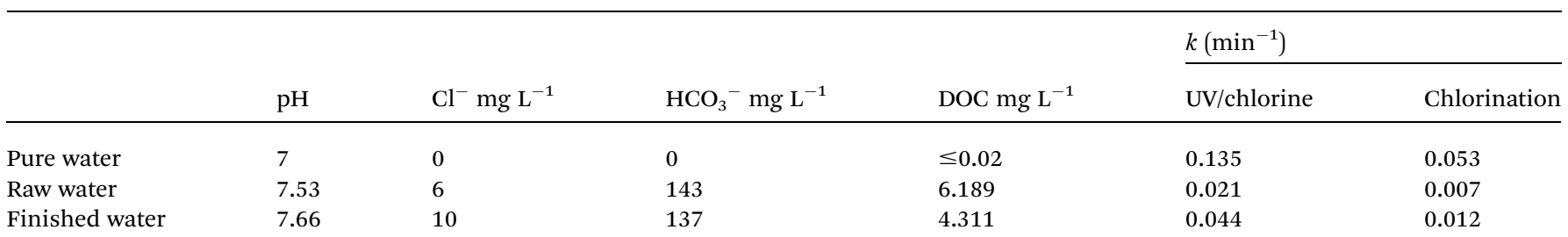

${ }^{a}[\mathrm{NPX}]_{0}=25 \mu \mathrm{M}$, [chlorine $]_{0}=250 \mu \mathrm{M}$, reaction time $=30 \mathrm{~min} .{ }^{b}$ All the water samples are filtered through $0.45 \mu \mathrm{m}$ hydrophilic polyethersulfone membrane. 


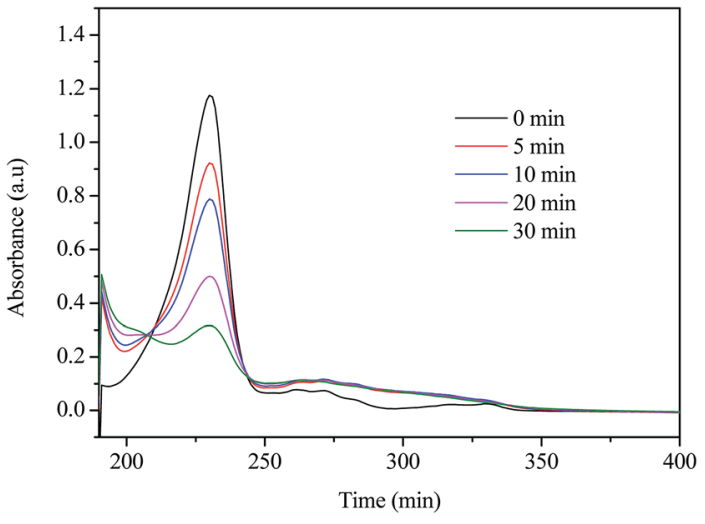

Fig. 5 The UV-vis spectra of the NPX degradation in UV/chlorine process. Conditions: $[\mathrm{NPX}]_{0}=25 \mu \mathrm{M}$, [chlorine $]_{0}=250 \mu \mathrm{M}, \mathrm{pH}=7$.

methoxyl groups on the naphthalene ring are two sites of the attack by $\mathrm{OH}$, and these two hydroxylated species can be further oxidized or demethylated to form P184 (2-methoxy-6vinylnaphthalene) and 2-(6-hydroxy-2-naphthyl)propanoic acid. ${ }^{34}$ However, we did not observe 2-(6-hydroxy-2-naphthyl) propanoic acid probably due to its fast transformation rate in our system. P200 is a typical photoinduced product of NPX under UV irradiation..$^{35}$ P200 is derived from the hydrogen abstraction of 1-(6-methoxy-2-naphthyl)ethanol, another photoinduced product that was not detected in our study; however, its oxidized precursor P187 was found. It has been demonstrated that decarboxylation is a main step in the degradation of NPX, and P187 corresponds to the decarboxylated product of NPX. ${ }^{36}$ Of note, P184 can also be formed by eliminating $\mathrm{H}_{2} \mathrm{O}$ molecule from 1-(6-methoxy-2-naphthyl) ethanol. ${ }^{37} \mathrm{Cl}$ is responsible for mono- and di-chloro NPX, corresponding to $\mathrm{P} 264$ and $\mathrm{P} 299$, respectively. In addition, two Clcontaining products can also be formed after electrophilic attack by chlorine on the naphthalene ring of NPX. ${ }^{38}$ P264 can then undergo decarboxylation, demethylation and hydrogen abstraction to yield P204, and P205 may also be derived directly from chlorine substitution in P184. In addition, P135 is attributed to a carboxylic acid, as the ultimate step in NPX mineralization. ${ }^{36}$ To conclude, these products in the UV/chlorine system reveal four main mechanisms, that is, hydroxylation, chlorine substitution of naphthalene, decarboxylation and demethylation. Based on the above discussion, the postulated degradation pathways of NPX during the UV/chlorine process are summarized in Fig. 6.

\subsection{Comparison of known DBPs formation during $\mathrm{UV} /$ chlorine and chlorination treatment}

Fig. 7 displayed the formation of chlorinated DBPs during the degradation of NPX by UV/chlorine and direct chlorination processes. Four kinds of chlorinated DBPs, namely trichloromethane (TCM), chloral hydrate (CH), dichloropropanone (DCP) and trichloropropanone (TCP), were detected. As seen, the concentration of TCM and $\mathrm{CH}$ increased or kept stable (DCP and TCP) as treatment was extended. Obviously, the formation of TCM, CH, and TCP was enhanced in the UV/ chlorine process compared to direct chlorination. Only 8.3\% mineralization was achieved for the UV/chlorine process under the tested conditions (date not shown), which indicates that NPX may transform into intermediates that more easily form DBPs after UV/chlorine treatment. ${ }^{39,40}$ It has been reported that the addition of a hydroxy group on the aromatic structure can increase the reactivity of compounds with chlorine, which results in the formation of DBPs precursors. ${ }^{41}$ Similar results were also reported by Wu et al., the formation of four tested DBPs in their study, including TCM, CH, dichloroacetonitrile (DCAN) and trichloroacetonitrile (TCNM), were enhanced in the UV/chlorine process compared to chlorination process. ${ }^{16}$ Therefore, this potential effect should be carefully considered in the practical use of the UV/chlorine process.

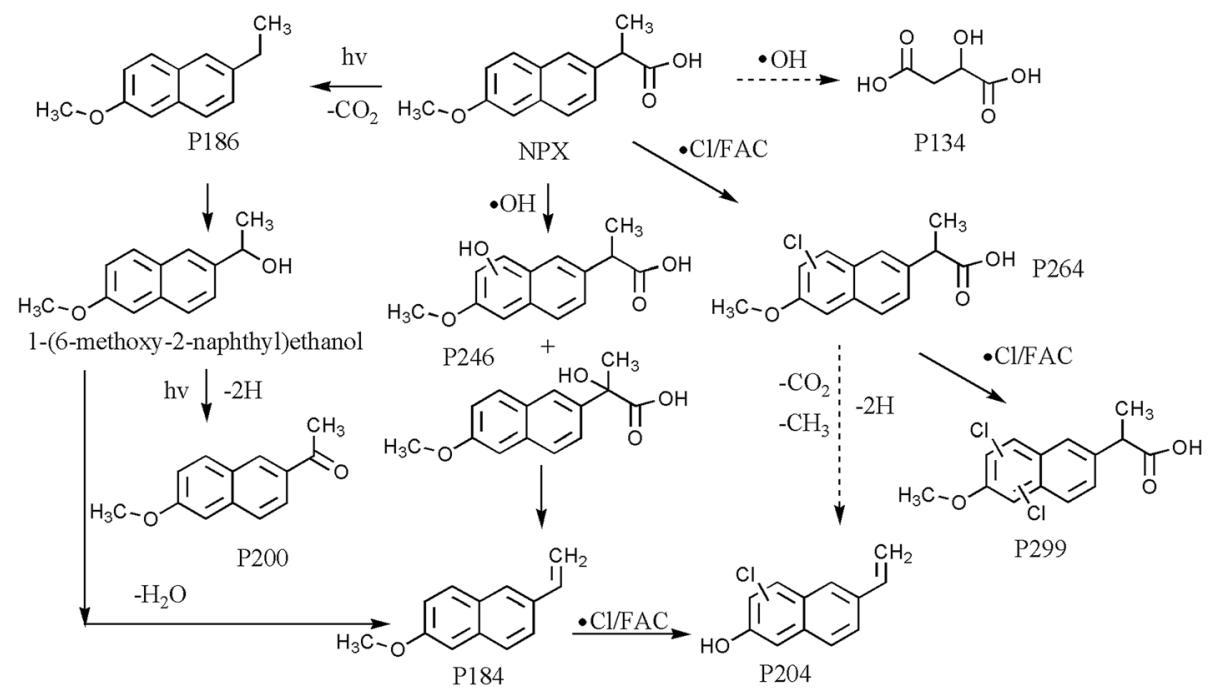

Fig. 6 Possible degradation pathways of NPX in UV/chlorine system. 

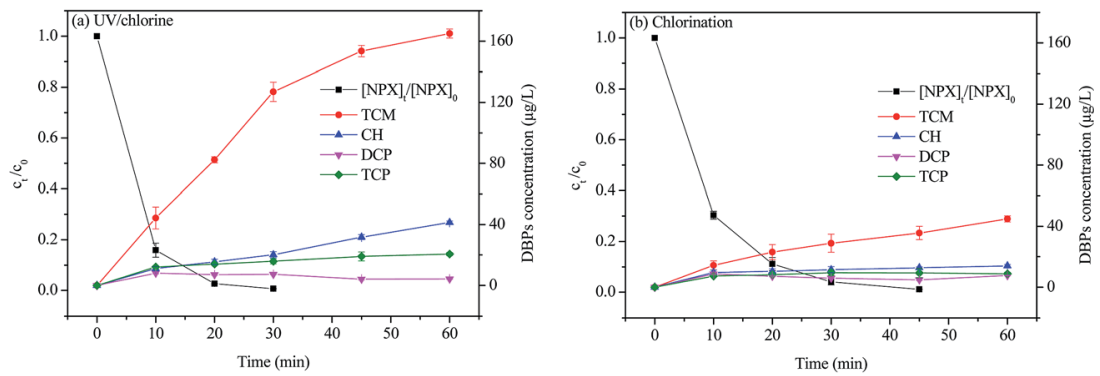

Fig. 7 The DBPs formation during NPX degradation by (a) UV/chlorine and (b) direct chlorination processes. Conditions: [NPX] $]_{0}=50 \mu M$, [chlorine $_{0}=500 \mu \mathrm{M}, \mathrm{pH}=7$.

\section{Conclusion}

This study investigated the degradation of NPX under different experimental conditions by a UV/chlorine AOP. The UV/chlorine process showed synergistic effects on NPX degradation compared to UV alone or direct chlorination. Both chlorination and radical oxidation are responsible for the degradation of NPX in the UV/chlorine process. In a typical UV/chlorine process, the pseudo-first-order rate constant of NPX increased as the initial chlorine dose increased and decreased as the solution $\mathrm{pH}$ increased. The presence of $\mathrm{Cl}^{-}$improves NPX degradation, while an inhibitory effect was observed in the presence of $\mathrm{HCO}_{3}{ }^{-}$and NOM. Analysis of the intermediate products by LC/MS/MS revealed that NPX decomposition in the $\mathrm{UV} /$ chlorine process was associated with hydroxylation, chlorine substitution of naphthalene, decarboxylation and demethylation. The UV/chlorine process has a risk of enhancing the formation of chlorinated DBPs compared to direct chlorination. This study demonstrates that the UV/chlorine process is a promising technology for removing NPX from contaminated water.

\section{Acknowledgements}

This work was supported by the Foundation of Key Laboratory of Yangtze River Water Environment, Ministry of Education, Tongji University, China (YRWEF201601) and the National Major Project of Science \& Technology Ministry of China (No. 2012ZX07403-001). We also thankful to the reviewers and editors for their valuable advice to improve this manuscript.

\section{References}

1 Q. W. Bu, B. Wang, J. Huang, S. B. Deng and G. Yu, J. Hazard. Mater., 2013, 262, 189-211.

2 D. Q. Zhang, R. M. Gersberg, W. J. Ng and S. K. Tan, Environ. Pollut., 2014, 184, 620-639.

3 B. Kasprzyk-Hordern, R. M. Dinsdale and A. J. Guwy, Water Res., 2009, 43, 363-380.

4 A. B. Caracciolo, E. Topp and P. Grenni, J. Pharm. Biomed. Anal., 2015, 106, 25-36.

5 K. Fent, A. A. Weston and D. Caminada, Aquat. Toxicol., 2006, 76, 122-159.
6 J. T. Yu, E. J. Bouwer and M. Coelhan, Agr. Water Manag., 2006, 86, 72-80.

7 T. A. Ternes, Water Res., 1998, 32, 3245-3260.

8 D. J. Lapworth, N. Baran, M. E. Stuart and R. S. Ward, Environ. Pollut., 2012, 163, 287-303.

9 F. Gagné, C. Blaise, M. Fournier and P. D. Hansen, Comp. Biochem. Physiol., Part C: Toxicol. Pharmacol., 2006, 143, 179-186.

10 M. Carballa, F. Omil, J. M. Lema, M. Llompart, C. GarcíaJares, I. Rodríguez, M. Gómez and T. Ternes, Water Res., 2004, 38, 2918-2926.

11 I. Sirés, E. Brillas, M. A. Qturan, M. A. Rodrigo and M. Panizza, Environ. Sci. Pollut. Res., 2014, 21, 8336-8367.

12 J. Y. Fang, Y. Fu and C. Shang, Environ. Sci. Technol., 2014, 48, 1859-1868.

13 M. J. Watts and K. G. Linden, Water Res., 2007, 41, 28712878.

14 X. J. Kong, J. Jiang, J. Ma, Y. Yang, W. L. Liu and Y. L. Liu, Water Res., 2016, 90, 15-23.

15 W. L. Wang, Q. Y. Wu, N. Huang, T. Wang and H. Y. Hu, Water Res., 2016, 98, 190-198.

16 Z. H. Wu, J. Y. Fang, Y. Y. Xiang, C. Shang, X. C. Li, F. G. Meng and X. Yang, Water Res., 2016, 104, 272-282.

17 Y. Feng, D. W. Smith and J. R. Bolton, J. Environ. Eng. Sci., 2007, 6, 277-284.

18 Z. B. Guo, Y. L. Lin, B. Xu, H. Huang, T. Y. Zhang, F. X. Tian and N. Y. Gao, Chem. Eng. J., 2016, 283, 412-419.

19 W. H. Chu, T. F. Chu, E. D. Du, Y. Deng, Y. Q. Guo and N. Y. Gao, Ecotoxicol. Environ. Saf., 2016, 124, 147-154.

20 S. Canonica, L. Meunier and U. von Gunten, Water Res., 2008, 42, 121-128.

21 W. H. Chu, N. Y. Gao, S. W. Krasner, M. R. Templeton and D. Q. Yin, Environ. Pollut., 2012, 161, 8-14.

22 V. J. Pereira, H. S. Weinberg, K. G. Linden and P. C. Singer, Environ. Sci. Technol., 2007, 41, 1682-1688.

23 G. R. Boyd, S. Y. Zhang and D. A. Grimm, Water Res., 2005, 39, 668-676.

24 G. V. Buxton, C. L. Helman, W. P. Helman and A. B. Ross, J. Phys. Chem. Ref. Data, 1998, 17, 513-886.

25 R. Mertens and C. von Sonntag, J. Photochem. Photobiol., A, 1995, 85, 1-9.

26 P. Wang, Y. L. He and C. H. Huang, Water Res., 2011, 45, 1838-1846. 
27 M. Q. Cai, L. Q. Zhang, F. Qi and L. Feng, J. Environ. Sci., 2013, 25, 77-84.

28 R. A. Trenholm, B. J. Vanderford, J. C. Holady, D. J. Rexing and S. A. Snyder, Chemosphere, 2006, 65, 1990-1998.

29 D. Wang, J. R. Bolton and R. Hofmann, Water Res., 2012, 46, 4677-4686.

30 L. M. Rebenne, A. C. Gonzalez and T. M. Olson, Environ. Sci. Technol., 1996, 30, 2235-2242.

31 G. V. Buxton and A. J. Elliot, Radiat. Phys. Chem., 1986, 27, 241-243.

32 C. Lee, J. Yoon and U. von Gunten, Water Res., 2007, 41, 581590.

33 J. R. Bolton, K. G. Bircher, W. Tumas and C. A. Tolman, Pure Appl. Chem., 2001, 73, 627-637.

34 N. Dulova, E. Kattel and M. Trapido, Chem. Eng. J., 2017, 318, 254-263.
35 R. Marotta, D. Spasiano, I. Di Somma and R. Andreozzi, Water Res., 2013, 47, 373-383.

36 D. Kanakaraju, C. A. Motti, B. D. Glass and M. Oelgemöller, Chemosphere, 2015, 139, 579-588.

37 T. K. Kim, B. R. Moon, T. Kim, M. K. Kim and K. D. Zoh, Chemosphere, 2016, 162, 157-164.

38 J. B. Quintana, R. Rodil, P. López-Mahía, S. MuniateguiLorenzo and D. Prada-Rodríguez, Water Res., 2010, 44, 243-255.

39 A. D. Dotson, V. O. S. Keen, D. Metz and K. G. Linden, Water Res., 2010, 44, 3703-3713.

40 D. A. Reckhow, K. G. Linden, J. Kim, H. Shemer and G. Makdissy, J. Am. Water Works Assoc., 2010, 102, 100-113. 41 G. Kleiser and F. Frimmel, Sci. Total Environ., 2000, 256, 1-9. 